\title{
DIAGNÓSTICO E TRATAMENTO DE COMPLICAÇÕES AGUDAS DO TRANSPLANTE DE CÉLULAS PROGENITORAS HEMATOPOÉTICAS
}

\author{
DIAGNOSIS AND TREATMENT OF ACUTE COMPLICATIONS OF \\ HEMATOPOIETIC STEM CELL TRANSPLANTATION
}

Eduardo JA Paton'; Marina A Coutinho ${ }^{1 \&}$ Júlio C Voltarelli²

\begin{abstract}
${ }^{1}$ Médicos assistentes da Unidade de Transplante de Medula Óssea do Hospital das Clínicas da FMRPUSP, ${ }^{2}$ Docente do Departamento de Clínica Médica da FMRPUSP e Coordenador da Unidade de TMO do HCFMRPUSP

CorResPondÊnCIA: Unidade de Transplante de Medula Óssea do Hospital das Clínicas da FMRPUSP. Campus Universitário - Ribeirão Preto, SP - CEP: $14048-900$
\end{abstract}

PATON EJA; COUTINHO MA \& VOLTARELLI JC. Diagnóstico e tratamento das complicações agudas do transplante de células progenitoras hematopoéticas. Medicina, Ribeirão Preto, 33: 264-277, jul./set. 2000.

RESUMO: Nesta revisão, são discutidos os princípios do diagnóstico e tratamento das principais complicações agudas, não infecciosas, do transplante de células progenitoras hematopoéticas: pancitopenia, incompatibilidade no sistema $A B O$, mucosite, doença veno-oclusiva hepática, cistite hemorrágica, pneumonite intersticial, cardiotoxicidade e doença do enxerto-contra-hospedeiro aguda. Oito casos clínicos, extraídos da casuística da nossa Unidade de TMO, são descritos brevemente para ilustrar aspectos particulares das doenças discutidas no trabalho.

UNITERMOS: Transplante de Medula Óssea. Doença Enxerto-Hospedeiro. Mortalidade; transplante.

\section{1- INTRODUÇÃO}

O desenvolvimento do transplante de células progenitoras hematopoéticas (TCPH), nas últimas décadas, permitiu o tratamento de doenças que, antes, eram invariavelmente fatais. A importância dessa abordagem terapêutica e de sua investigação clínica foi reconhecida com a atribuição do prêmio Nobel de Medicina, em 1990, ao Dr. E. Donnall Thomas, de Seattle, EUA, um dos pioneiros da introdução do TCPH na espécie humana ${ }^{(1)}$.

Inúmeras são as doenças que podem ser tratadas pelo TCPH em suas várias modalidades: singênico, autólogo ou alogênico; de medula óssea, sangue periférico ou de cordão umbilical; de doadores apa- rentados ou não relacionados, imunogeneticamente compatíveis (HLA-idêntico) ou incompatíveis, manipulados (com depleção de células T ou neoplásicas) ou não, utilizando regimes de condicionamento mieloablativos ou subablativos, etc (vide Capítulo VII na segunda parte deste Simpósio). Algumas das doenças tratadas com TCPH estão listadas na Tabela I.

Os pacientes são preparados ou condicionados para o TCPH com quimioterapia em altas doses associada ou não à radioterapia. O regime de condicionamento clássico provoca mieloablação, que permite criar espaço na cavidade da medula óssea (MO), induz imunossupressão e trata a doença residual. Deste modo, permite a enxertia das CPH transplantadas, que são responsáveis pela reconstituição da hematopoese, 
que começa a se revelar no sangue periférico de 2 a 3 semanas após a infusão das células, período este caracterizado por intensa aplasia medular e pancitopenia periférica $^{(2,3)}$.

As complicações decorrentes do período de aplasia são as infecções, os sangramentos e a anemia. Os pacientes são hospitalizados em isolamento e cuidados por uma equipe multidisciplinar altamente treinada, com o objetivo de reduzir o risco de infecções e das outras complicações. Hemoderivados e terapêutica antimicrobiana são utilizados até a recuperação hematológica. A fim de facilitar a coleta de sangue e a supressão de medicamentos, um acesso intravenoso central de uso contínuo é providenciado previamente ao transplante. As CPH são infundidas através deste acesso e encontram o seu caminho para a medula óssea num fenômeno conhecido com homing, onde as células se fixam ao estroma da medula e começam a proliferar e a se diferenciar para reconstituir os sistemas hematopoético e imune.

As complicações subseqüentes incluem os efeitos tóxicos extramedulares do regime de condiciona- mento, sendo um dos principais deles a doença venooclusiva hepática ou VOD, a rejeição do enxerto e o desenvolvimento da doença do enxerto-contra-hospedeiro (DECH ou, do inglês, GVHD, graft-versus-host disease) aguda.

As complicações mais tardias incluem a DECH crônica, a pneumonite intersticial, as infecções virais, as anormalidades endocrinológicas e a recidiva da doença básica, as quais serão tratadas em outro capítulo na segunda parte deste Simpósio. As crianças podem ainda apresentar problemas específicos relacionados ao condicionamento, como retardo de crescimento e de desenvolvimento neurológico e alterações hormonais (vide Capítulo III deste Simpósio).

$\mathrm{O}$ estudo das complicações agudas do TCPH pode ser dividido, para fins didáticos, em 1) complicações relacionadas ao período de aplasia medular e de imunossupressão, em particular as infecções pós-transplante, que serão analisadas em um capítulo próprio, em seguida a este, 2) complicações extramedulares relacionadas ao condicionamento e 3 ) as relacionadas à DECH aguda.

Tabela I - Doenças tratadas com transplante de células tronco hematopoéticas

DOENÇAS NEOPLÁSICAS

Leucemias

- Leucemia mielóide aquda

- Leucemia linfóide aquda

- Leucemia mielóide crônica

- LMC juvenil

- Síndromes Mielodisplásticas

- Leucemias e SMD secundárias

- Leucemia linfóide crônica

Doencas linfoproliferativas

- Linfoma de Hodgkin

- Linfomas não-Hodgkin

- Mieloma múltiplo

Tumores sólidos

- Neuroblastoma

- Câncer de mama

- Câncer testicular

- Câncer de ovário

- Câncer pulmonar de pequenas células
DOENÇAS NÃO NEOPLÁSICAS

Falências medulares adquiridas

Anemia Aplástica Grave

Hemoglobinúria paroxística noturna

Falências medulares hereditárias

- Anemia de Fanconi

- Síndrome de Diamond-Blackfan

- Agranulocitose de Kostmann

- Histiocitose eritrofagocítica familiar

- Disceratose congênita

- Síndrome de Shwachman-Diamond

Hemoqlobinopatias:

- Talassemia maior

- Anemia falciforme

\section{Deficiências imunolóqicas}

- Imunodeficiência combinada grave (SCID)

- Síndrome de Wiskott-Aldrich

- Doença granulomatosa crônica infantil

Erros inatos do metabolismo

- Doença de Gaucher

- Síndrome de Hunter 


\section{2- COMPLICAÇÕES RELACIONADAS AO PERÍODO DE APLASIA MEDULAR}

As abordagens que permitem o encurtamento do período de aplasia medular pós-TCPH, como o uso de células progenitoras hematopoéticas obtidas a partir do sangue periférico e de fatores de crescimento hematopoéticos, bem como a evolução dos suportes hemoterápico e antimicrobiano, proporcionaram uma redução notável na incidência e gravidade das complicações secundárias à pancitopenia e, conseqüentemente, da morbi-mortalidade relacionada ao transplante.

Embora a capacidade das células progenitoras hematopoéticas presentes no sangue periférico (CPHSP) fosse conhecida desde o final dos anos 70, somente em meados dos anos 80, com a disponibilidade dos fatores de crescimento hematopoéticos ${ }^{(4)}$, foi possível mobilizar e coletar grande número de CPHSP através de citaféreses. A infusão destas células permite uma rápida recuperação hematológica, além de facilitar a manipulação e expansão de componentes do material coletado. Conseqüentemente, a principal fonte de CPH para transplante autólogo, atualmente, é o sangue periférico. Diante das vantagens conferidas pelo uso de CPHSP no transplante autólogo, o uso do sangue periférico foi ampliado para o transplante alogênico nos anos 90, mas a comparação entre estas duas modalidades, em estudos prospectivos randomizados, não está concluída. Embora existisse o temor de que o maior número de linfócitos $\mathrm{T}$ existentes no sangue periférico mobilizado pudesse aumentar a incidência e a gravidade da DECH aguda, os dados iniciais deixaram de confirmar esta hipótese, porém existem evidências consistentes de que a incidência de DECH crônica deve ser maior em decorrência do uso de CPHSP, o que não tem impedido a crescente substituição do TMO alogênico pelo TCPHSP. Inúmeros fatores recombinantes de crescimento hematopoéticos e outras citocinas foram desenvolvidos nos últimos anos e estão envolvidos na regulação do crescimento e diferenciação das linhagens de células hematopoéticas. A Tabela II enumera alguns destes fatores, a linhagem das células alvo de sua ação, bem como seu uso terapêutico em TCPH. Assim, os fatores de crescimento utilizados rotineiramente no TCPH são: 1) a eritropoetina (EPO), a principal proteína reguladora da eritropoese, a qual se tem mostrado efetiva na redução das necessidades transfusionais de eritrócitos e aceleração da enxertia eritróide pós-TCPH alogênico em inúmeros estudos controlados ${ }^{4 a)}$; ela não tem sido largamente utilizada em nosso meio devido ao alto custo; 2) o G-CSF e o GM-CSF (fatores estimuladores de colônias granulocitárias e macrofágicas/ granulocitárias, respectivamente), envolvidos na regulação da diferenciação e proliferação de granulócitos e/ou monócitos, são utilizados, tanto na fase de mobilização e coleta de CPHSP, quanto no período pós-transplante, permitindo a aceleração da recuperação hematológica e o resgate da hematopoese em pacientes com falha de enxertia; 3) a IL-2, empregada como estimuladora do sistema imune para prevenção ou tratamento de recaídas neoplásicas. Outros fatores de crescimento listados na tabela, alguns atuando sobre a própria $\mathrm{CPH}$ ou sobre precursores megacariocitários ou linfóides, deverão entrar em uso clínico nos próximos anos e contribuir para a redução dos efeitos da pancitopenia no TCPH.

$\mathrm{Na}$ grande maioria dos transplantes alogênicos HLA-idênticos relacionados, a falha de enxertia (primária ou secundária, de causa imunológica ou não) é uma ocorrência bastante rara, embora bastante grave, porque a pancitopenia intensa e prolongada tem uma alta taxa de mortalidade. A falha de enxertia costuma

\begin{tabular}{|lll|}
\hline \multicolumn{2}{|l|}{ Tabela II - Fatores de crescimento hematopoético utilizados em TCPH } \\
\hline Fator de crescimento & Linhagem celular alvo & Uso clínico em TCPH \\
\hline G-CSF & Mielóide & Rotina \\
GM-CSF & Mielóide/Macrofágica & Rotina \\
IL-3 & Mielóide & Investiqação \\
Eritropoetina & Eritróide & Rotina \\
PIXY321 & Mielóide & Investigação \\
MGDF* e Trombopoetina & Megacariocitária & Investigação \\
IL-2 & Linfóide & Rotina/Investigação \\
SCF & Mielóide/Linfóide & Investigação \\
M-CSF & Macrofágica/Monocítica & Investigação \\
IL-11 & Megacariocitária & Investiqação \\
\hline GM-CSF: Granulocytic-Macrophagic Colony Stimulating Factor. MGDF: Megakaryocyte \\
\hline Growth and Development Factor. SCF: Stem Cell Factor.
\end{tabular}


ocorrer mais frequentemente em pacientes politransfundidos portadores de anemia aplástica adquirida (vide Capítulo I) e em pacientes que recebem transplantes não relacionados, HLA incompatíveis, depletados de células T ou com baixas doses de CPH (por exemplo, transplantes de sangue de cordão umbilical em adultos). Nos transplantes autólogos, por sua vez, a falha ou retardo de enxertia está relacionada, na maioria das vezes, a um número insuficiente de $\mathrm{CPH}$ viáveis no enxerto ou a recidiva da doença básica.

$O$ suporte transfusional dos pacientes submetidos a TCPH apresenta características peculiares decorrentes da necessidade de 1) minimizar a aloimunização anti-eritrocitária e anti-plaquetária e antitecidual através da leucodepleção dos componentes hemoterápicos celulares e da seleção criteriosa de doadores compatíveis; 2) da prevenção da DECH transfusional através da irradiação dos hemocomponentes celulares, que evita esta complicação pela inibição da ativação e proliferação das células T alorreativas; 3) diminuir o risco das doenças infecciosas transmitidas pelas transfusões, principalmente a infecção pelo citomegalovírus (CMV), que é minimizada pela leucodepleção dos componentes celulares e/ou pela seleção de doadores que apresentam sorologia negativa para o vírus (menos de $10 \%$ dos doadores em nosso meio). De particular interesse é a abordagem das incompatibilidades no sistema $\mathrm{ABO}$ entre doadores e receptores de TCPH e da compreensão das anormalidades cinéticas da eritropoese que acompanham estas incompatibilidades. Basicamente, na ocorrência de incompatibilidade $\mathrm{ABO}$ maior (anticorpos no receptor contra antígenos eritrocitários do doador), especialmente com títulos elevados de anticorpos, medidas que visam à remoção dos glóbulos vermelhos do produto de CPH do doador (deseritrocitação) ou dos anticorpos anti-eritrocitários do soro do receptor (através de plasmaféreses, por exemplo) devem ser instituídas ${ }^{(5,6)}$. A adoção destas medidas permite cruzar as barreiras de compatibilidade ABO com certa facilidade nos TCPH, mas, raramente, observam-se reações hemolíticas graves, como ilustrado no caso clínico $N^{o} 1$ relatado abaixo.

\section{CASO CLÍNICO ILUSTRATIVO $\mathbf{N}^{\circ} 1$}

Paciente de 31 anos do sexo masculino, portador de leucemia mielóide crônica em fase crônica, foi transplantado em novembro/92 com a medula óssea de sua única irmã HLA-idêntica, multípara (8 gestações) e ABO incompatível (paci- ente do grupo $O$ e doadora do grupo B). Foram feitas três sessões de plasmaférese no receptor, previamente ao transplante, reduzindo-se os títulos de isohemaglutinina anti-B de 1:64 para 1:16. $O$ condicionamento foi feito com bussulfan $16 \mathrm{mg} /$ $\mathrm{Kg}$ e ciclofosfamida $120 \mathrm{mg} / \mathrm{Kg}$ e o paciente desenvolveu uma reação hemolítica imediata e grave, traduzida por choque circulatório, após a infusão de $10 \mathrm{ml}$ de medula óssea. O quadro clínico foi revertido com medidas de suporte hemodinâmico (hiperhidratação e vasopressores). Após duas outras sessões de plasmaférese e da transfusão lenta de $60 \mathrm{ml}$ de concentrado de hemácias do tipo $B$, para adsorver in vivo os anticorpos anti-B, a medula óssea foi infundida sem problemas. No período pancitopênico, o paciente ainda desenvolveu febre, esteatose hepática secundária à nutrição parenteral e refratariedade a plaquetas responsiva a trombocitaféreses do doador. A enxertia da medula óssea foi detectada no dia +12 , concomitante a DECH aguda de fígado, tubo digestivo e pele, que respondeu rapidamente à corticoterapia. Entretanto, no dia +27 , quando a dose do corticoesteróide estava sendo reduzida, desenvolveu sepse oligossintomática por $\boldsymbol{E}$. coli (episódio único de febre baixa) e foi a óbito em poucas horas.

COMENTÁRIOS: Este paciente, o terceiro a ser transplantado na Unidade de TMO do HCFMRP, desenvolveu reação hemolítica grave por incompatibilidade ABO maior, apesar de se ter obtido redução dos níveis de isohemaglutininas de classe IgM para níveis considerados seguros (1:16). Uma análise retrospectiva mostrou a presença de título moderadamente alto de anticorpos anti-B de classe IgG (1:64) no momento do transplante, o que deve ter sido a causa principal da hemólise neste caso. Atualmente, empregamos rotineiramente nos TCPH com incompatibilidade ABO maior, a deseritrocitação da medula óssea do doador, associada a plasmaférese do receptor, quando necessária. O paciente apresentou outras complicações agudas do TMO, a principal delas sendo uma septicemia por Gram-negativo na vigência de corticoterapia, causando poucas manifestações inflamatórias e evoluindo rapidamente para choque circulatório e óbito. Esta ocorrência suporta a prática, adotada em alguns centros de transplante, de se colher hemoculturas de vigilância em pacientes submetidos a corticoterapia, mesmo em fases avançadas pós-TMO. 


\section{3- TOXICIDADE EXTRAMEDULAR DO RE- GIME DE CONDICIONAMENTO}

Vários sistemas orgânicos são lesados significativamente pelos regimes intensivos de quimioterapia e/ou radioterapia empregados na preparação para o TCPH. Estudos toxicológicos cuidadosos permitem predizer a recuperação da maioria dos pacientes submetidos a estes regimes, mas a variação individual e inúmeros fatores de comorbidade podem potenciar a gravidade destas lesões tóxicas e conduzir a seqüelas importantes ou, mesmo, ao êxito letal. Discutiremos abaixo as principais complicações extramedulares dos regimes de condicionamento empregados nos TCPH.

\subsection{Mucosite}

A descamação das mucosas oral e faringeana provocada pelo regime de condicionamento é caracterizada pele presença de dor, inicialmente desencadeada pela deglutição, de intensidade variável conforme o grau do comprometimento e da sensibilidade individual de cada paciente, freqüentemente requerendo o uso de analgésicos opióides. Em casos mais graves, pode ocorrer obstrução de vias aéreas superiores por edema ou por placas de mucosa descamadas, como ilustrado no caso clínico $N^{o} 2$ descrito abaixo. Infecções, especialmente pelo herpes simples, além do uso de Metotrexate (MTX) na profilaxia da DECH, podem contribuir para a gravidade da mucosite. $\mathrm{O}$ uso de ácido folínico em dose equivalente ao MTX pode minimizar os efeitos da droga sobre a mucosa, como observado em alguns trabalhos ${ }^{(7)}$. Em nosso serviço, no último ano, estamos administrando Leucovorin 24 horas após a administração do Metotrexate na mesma dose do MTX usada na profilaxia da DECH $\left(15 \mathrm{mg} / \mathrm{m}^{2}\right.$ no dia +1 e $10 \mathrm{mg} / \mathrm{m}^{2}$ nos dias $+3,+6$ e +11$)$, na tentativa de amenizar alguns de seus efeitos adversos, como a piora da mucosite e da VOD hepática e o retardo na enxertia da medula óssea. Estamos observando, embora ainda sem comprovação estatística, que os pacientes têm apresentado quadros menos graves de mucosite, desde a introdução desta estratégia terapêutica.

\section{CASO CLÍNICO ILUSTRATIVO No 2}

Paciente de 40 anos, masculino, submetido a TMO alogênico de irmão HLA idêntico por leucemia mielóide crônica em fase crônica, condicionado com BUCY2 (Bussulfan $16 \mathrm{mg} / \mathrm{Kg} e$ Ciclofosfamida $120 \mathrm{mg} / \mathrm{Kg}$ ). Recebeu Mesna $150 \%$ da dose de ciclofosfamida, dividida em 3 infusões endovenosas (1, 4 e 8 h após a ciclofosfamida) $e$ profilaxia de DECH com ciclosporina $A+$ metotrexate. No dia +5 iniciou odinofagia e parada da ingestão oral, sendo iniciada nutrição parenteral e gargarejos com uma mistura de benzidamida, micostatin e tetracaína (fórmula antimucosite). No dia +7 apresentava a orofaringe hiperemiada com lesões esbranquiçadas em toda a mucosa oral e faringeana e referia piora da odinofagia, necessitando do uso de opióides. As lesões orais pioraram, com erosões em toda a mucosa oral e na língua, sangramento oral e digestivo alto resistente à transfusão de glóbulos vermelhos, plaquetas e crioprecipitado. No dia +19 , houve sangramento profuso da mucosa oro-faringeana e o paciente evoluiu para óbito por aspiração maciça de sangue e coágulos com obstrução das vias aéreas, sem que tivesse ocorrido ainda enxertia da medula óssea.

COMENTÁRIOS: Houve uma evolução catastrófica de mucosite grave, não afetada pelo tratamento de suporte (narcóticos, hemoderivados e soluções tópicas). No futuro, novas abordagens terapêuticas em investigação, como fatores de crescimento epitelial (fator de crescimento de queratinócitos, IL-11 e TGF-beta, por exemplo), poderão acelerar a reepitelização das mucosas no período pós-condicionamento e evitar a progressão e as conseqüências graves da mucosite, como as observadas neste caso.

\subsection{Náuseas, vômitos e diarréia}

Náuseas, vômitos e anorexia que ocorrem nas primeiras 2 a 3 semanas do TCPH têm, como principal causa, o regime de condicionamento. A persistência destes sintomas por períodos mais prolongados podem ser causada por DECH aguda, infecções (CMV, herpes simples) ou toxicidade medicamentosa. A identificação dos fatores causais associada a regime antiemético individualizado às necessidades de cada paciente permite, em geral, um controle eficaz dos sinto$\operatorname{mas}^{(8)}$. Não se deve usar, de modo indiscriminado e prolongado, inibidores potentes da secreção ácida do estômago (agindo sobre os receptores $\mathrm{H} 2$ ou sobre a bomba de prótons), pois eliminam uma barreira importante contra a invasão microbiana no tubo digestivo.

A causa mais comum de diarréia nas primeiras 2 a 3 semanas após o TCPH é a toxicidade do regime de condicionamento. Após este período, a DECH torna-se o fator etiológico mais importante, porém as causas infecciosas devem sempre ser descartadas em qual- 
quer fase do TCPH como causa de diarréia. Os principais agentes etiológicos de diarréias infecciosas no período pós-TCPH precoce são o Chlostridium difficile, os bacilos gram-negativos (Pseudomonas, Aeromonas, Acinetobacter) agentes virais (astrovírus adenovírus, rotavírus, CMV) e fungos (Candidas e outros). Na presença de diarréias volumosas, as medidas de restrição dietética (vide Capítulo específico na $2^{a}$ parte deste Simpósio), a manutenção do equilíbrio hidroeletrolítico e a abordagem direta da causa devem ser iniciadas. O octreotide, um análogo da somatostatina que inibe a secreção líquida no intestino, pode ser útil como adjuvante no tratamento das diarréias secretórias, principalmente associadas à DECH aguda.

\subsection{Cistite hemorrágica}

A frequiência de cistite hemorrágica pós-TCPH varia na literatura de 5 a $50 \%$. O uso de altas doses de ciclofosfamida e a ocorrência de infecções virais do trato urinário, especialmente as causadas pelo adenovírus e pelos poliomavírus (vírus $\mathrm{BK}$ e JK) e, menos freqüentemente, pelo CMV, são as causas principais desta complicação. Na sua prevenção, pode ser usado Mesna, que inativa a acroleína, um metabolito da ciclofosfamida que é tóxico para a bexiga, ou uma combinação de hiperhidratação e irrigação vesical. Esta mesma combinação é usada no tratamento da cistite hemorrágica, visando à prevenção da formação de coágulos e da obstrução urinária. A manutenção de um nível adequado de plaquetas em circulação é recomendada e a infusão intravesical de prostaglandina E1, G-CSF, formalina ou alúmen e o uso de câmaras de oxigenioterapia hiperbárica podem ser benéficos em casos refratários, como ilustrado pelo caso clínico $N^{o} 3$ apresentado abaixo. Medidas mais radicais, como cistostomia, cistectomia ou interrupção da irrigação sanguínea da bexiga, têm alta morbi-mortalidade, mas mostraram sucesso limitado em casos clínicos esporádicos relatados na literatura ${ }^{(9)}$. Entretanto, o momento adequado para se indicar estas medidas nem sempre é fácil de determinar, como mostrado no caso clínico $N^{o} 4$.

\section{CASO CLÍNICO ILUSTRATIVO No 3}

Paciente de 28 anos de idade, do sexo masculino, submetido a transplante alogênico de medula óssea de irmão HLA idêntico por LMA-M2 em primeira remissão completa, condicionado com BUCY2 (Bussulfan $16 \mathrm{mg} / \mathrm{Kg}$ e Ciclofosfamida $120 \mathrm{mg} / \mathrm{Kg}$ ). Recebeu Mesna e profilaxia da DECH com ciclosporina $A+$ metotrexate. A enxertia da medula óssea ocorreu no dia +19 e no dia +23 iniciou quadro de hematúria microscópica que evoluiu para sangramento urinário franco no dia +34 . A cistoscopia revelou sangramento difuso da mucosa e a histologia não mostrou evidências de etiologia específica. O sangramento urinário não apresentou melhora com hiperhidratação, irrigação vesical contínua, transfusão maciça de plaquetas e instilação intravesical de protaglandina E1. No dia +44 foi iniciada oxigenioterapia hiperbárica realizada em câmara hiperbárica do Hospital da Marinha do Rio de Janeiro, utilizando $100 \% \mathrm{O}_{2}$ a 2.0 atmosferas de pressão por 6090 minutos/sessão. Após 26 sessões, houve remissão completa do sangramento urinário e, atualmente, o paciente está no D+450 pós-TMO em remissão completa da LMA.

\section{CASO CLÍNICO ILUSTRATIVO $\mathbf{N}^{\circ} 4$}

Paciente de 19 anos, masculino, submetido a TMO alogênico de irmã HLA idêntica por síndrome mielodisplástica hipoplástica, condicionado com BUCY2 (Bussulfan $16 \mathrm{mg} / \mathrm{Kg} e$ Ciclofosfamida $120 \mathrm{mg} / \mathrm{Kg})$. Recebeu Mesna e profilaxia da DECH com ciclosporina $A+$ metotrexate. A enxertia da medula ocorreu no dia +11 e no dia +34 apresentou disúria e hematúria macroscópica e foi iniciado tratamento com hiperhidratação. A cistoscopia mostrou mucosa vesical edemaciada e hiperemiada e a histologia revelou processo inflamatória crônico inespecífico com edema e ectasia vascular. Pesquisa viral para poliomavírus foi negativa. No dia +44 iniciou irrigação vesical contínua com salina gelada por ter evoluído com piora da hematúria e formação de grandes e freqüentes coágulos. O sangramento foi resistente às medidas tomadas de hiperhidratação, irrigação vesical $e$ instilação vesical de prostaglandina E1 e G-CSF. Necessitou de várias cistoscopias para a retirada de coágulos. Evoluiu com plaquetopenia refratária à transfusão maciça de plaquetas, fungemia por Fusarium sp $e$ insuficiência renal pós-renal. No dia +91 foi a óbito por choque hemorrágico após realização de cistoscopia complicada por laceração da mucosa vesical.

COMENTÁRIOS: Este paciente não teve condições clínicas para ser encaminhado a outro centro para a realização da oxigenoterapia hiperbárica, como o paciente descrito anteriormen- 
te. O óbito por acidente de cistostocopia ocorreu quando estavam em consideração medidas terapêuticas mais radicais, como a cistectomia ou a ligação das artérias hipogástricas. Não foram tentadas instilações intravesicais com alúmen ou formaldeído devido à alta morbidade e baixa resolutividade.

\subsection{Doença veno-oclusiva hepática (VOD)}

A incidência da VOD varia de 5 a $55 \%$ e a doença se caracteriza por hepatomegalia ou dor na região do hipocôndrio direito, ganho de peso sem outras causas aparentes e hiperbilirrubinemia, que surgem, na maioria das vezes, até 30 dias após o TCPH. A complicação é decorrente da obstrução não trombótica das vênulas intrahepáticas com lesão subseqüente dos hepatócitos e sinusóides centrolobulares adjacentes (zona 3 do ácino hepático). Os achados histológicos compreendem, desde um edema subendotelial com congestão centrolobular, até degeneração hepatocelular com fibrose das vênulas centrais e sinusóides centrolobulares, acarretando obstrução do fluxo sangüíneo venoso e hipertensão portal intra-hepática. Biópsia por via transjugular pode ser necessária, em casos limitados, para auxiliar o diagnóstico diferencial com $\mathrm{DECH}$, hepatites virais, fúngicas ou medicamentosas. A gravidade da VOD foi definida retrospectivamente pelo grupo de Seattle e, embora a taxa de mortalidade geral da complicação seja de aproximadamente $30 \%$, nos casos mais leves que não necessitam de tratamento específico ela está em torno de $8 \%$, enquanto que nos casos mais graves, com comprometimento de múltiplos órgãos, praticamente todos os pacientes vão a óbito (98\%). Uma rápida e precoce elevação das bilirrubinas, associada a um acentua- do ganho de peso, são indicativos de mau prognóstico, que pode ser estimado em curvas atuariais contendo estes parâmetros ${ }^{(8)}$. O tratamento da VOD é essencialmente de suporte, com manutenção do equilíbrio hidro-eletrolítico, restrição sódica e suporte transfusional. Vários estudos foram realizados com abordagens profiláticas da VOD (Tabela III), visando a diminuir a incidência e a gravidade da complicação ${ }^{(10-15)}$.

Estudos recentes ${ }^{(16)}$ sugerem que o uso do ativador do plasminogênio tecidual recombinante (TPAr), em baixas doses combinado à heparina, nas fases precoces da VOD, pode alterar a evolução em casos de pior prognóstico, como sugerido no caso clínico $N^{o} 5$ descrito abaixo. Novos agentes anti-trombóticos, como o polidesoxirribonucleotídeo ou defibrotide, que não possui efeito anticoagulante sistêmico, estão sendo estudados com resultados iniciais promissores $^{(17)}$. Na VOD grave, já estabelecida, poucas alternativas terapêuticas estão disponíveis, entre elas o "shunting" porto-cava e o transplante hepático.

\section{CASO CLÍNICO ILUSTRATIVO $\mathbf{N}^{\circ} 5$}

Paciente de 39 anos, masculino, submetido em agosto de 1997 a transplante alogênico de medula óssea de irmão HLA-idêntico, por leucemia mielóide crônica em fase crônica, sendo condicionado com BUCY2 (Bussulfan $16 \mathrm{mg} / \mathrm{Kg} e$ Ciclofosfamida $120 \mathrm{mg} / \mathrm{Kg}$ ), associado a Mesna e profilaxia de DECH com ciclosporina $A+$ metotrexate. Teve como complicações pós-TMO mucosite grau II, insuficiência renal aguda, reativação de moléstia de Hansen e doença venooclusiva hepática, que se iniciou no dia +8 quando o paciente apresentou hiperbilirrubinemia de

\begin{tabular}{|llll}
\hline \multicolumn{2}{l}{ Tabela III - Estudos controlados de profilaxia da VOD } & \\
\hline AUTOR (ANO) & AGENTE & RESULTADOS & OBSERVAÇÕES \\
\hline Attal (1992) & Heparina contínua, em baixas doses & Positivos & Pacientes de baixo risco \\
Or (1996) & Heparina de baixo peso molecular & Positivos & Não randomizado \\
Lee (1996) & & & \\
Gluckman (1990) & Prostaglandina E1 & Positivos & Demonstrado apenas neste estudo \\
Comcowich (1997) & Ursodiol & Duvidosos & Pequena amostragem \\
Ohashi (2000) & Ursodiol & Positivos & Estudo randomizado
\end{tabular}


2,2 $\mathrm{mg} / \mathrm{dl}$ e hepatomegalia. Houve piora progressiva do estado geral, com aumento do volume abdominal, dor à palpação do hipocôndrio direito e aumento dos níveis de bilirrubina, que, no dia +15 , eram de 15,3 mg/dl. Nesta data, recebeu TPA-r na dose de $10 \mathrm{mg} /$ dia por dois dias e heparina 1000 $U$ EV em bolo e a seguir $150 \mathrm{mg} / \mathrm{Kg} / \mathrm{dia}$ em infusão contínua. No dia +20 a bilirrubina total atingiu de 37,9 mg/dl e, a partir dessa data, houve redução progressiva da hiperbilirrubinemia, da hepatomegalia e do volume abdominal. O paciente teve enxertia da medula óssea no dia +16 e alta da unidade no dia +30 , permanece vivo e em remissão da LMC mais de três anos após o TMO.

\section{CASO CLÍNICO ILUSTRATIVO $\mathbf{N}^{\circ} 6$}

Paciente de 16 anos, feminina, submetida a transplante alogênico de medula óssea de irmão HLA-idêntico por síndrome mielodisplástica hipoplástica, condicionada com BUCY2 (Bussulfan $16 \mathrm{mg} / \mathrm{Kg}$ e Ciclofosfamida $120 \mathrm{mg} / \mathrm{Kg}$ ), recebeu Mesna $180 \mathrm{mg} / \mathrm{Kg}$ e profilaxia de DECH com ciclosporina $A+$ metotrexate. No dia +3 apresentou hiperbilirrubinemia, inicialmente de 4,3 $\mathrm{mg} / \mathrm{dl}$, aumento discreto do volume abdominal $e$ hepatomegalia dolorosa. Houve piora progressiva da dor em hipocôndrio direito, aumento de peso, extrema dificuldade no manejo do balanço hídrico, piora dos níveis de bilirrubina total, que no dia +15 eram de $12 \mathrm{mg} / \mathrm{dl}$ e insuficiência renal aguda. A paciente evoluiu para óbito no dia +16 por falência de múltiplos órgãos, antes que ocorresse enxertia da medula óssea.

COMENTÁRIOS: Este paciente apresentou, concomitantemente ao quadro hepático, plaquetopenia refratária e sangramento digestivo, que contraindicaram o uso de TPA-r. O comprometimento renal, associado à VOD grave, piora bastante a evolução do quadro clínico, como ocorreu neste caso.

\subsection{Complicações pulmonares}

As complicações pulmonares de causas não infecciosas podem ocorrer em até $30 \%$ dos pacientes submetidos a TCPH. A hemorragia alveolar difusa ocorre em torno de 2 semana após o TCPH, tanto autólogo quanto no alogênico e tem etiologia desconhecida. Caracteriza-se por consolidação difusa na ra- diografia de tórax, hipoxemia progressiva e ausência de crescimento de agentes microbianos no lavado bronco-alveolar, que tem aspecto sangüinolento. A mortalidade é de 80 a $100 \%$ e o tratamento com altas doses de corticosteróides pode trazer algum benefício $^{(18)}$. A pneumonite intersticial idiopática (PII) é definida pelos seguintes critérios: a) evidência de dano alveolar extenso, revelado por infiltrados multilobulares; b) sintomas clínicos de pneumonia, tais como tosse, febre e dispnéia; c) alterações na fisiologia pulmonar, com alterações restritivas ou aumento do gradiente de oxigênio alvéolo-arterial; d) ausência de infecção no lavado bronco-alveolar. Esta complicação pode ocorrer de 14 a 80 dias após o TCPH (geralmente, por volta do $45^{0}$ dia) e está associada ao regime de condicionamento, principalmente à irradiação corporal total e à quimioterapia com $\mathrm{BCNU}$, bussulfan e ciclofosfamida. A mortalidade é da ordem de $95 \%$ nos casos que evoluem para assistência ventilatória, como ocorreu no caso relatado abaixo $\left(N^{o} 7\right)$. $\mathrm{O}$ uso de altas doses de corticosteróides precocemente pode impedir a evolução fatal numa minoria de casos de PII ${ }^{(19,20)}$.

\section{CASO CLÍNICO ILUSTRATIVO No 7}

Paciente de 33 anos, masculino, submetido em julho de 1997 a TCPH autólogo de sangue periférico por doença de Hodgkin, condicionado com BEAM (BCNU 300mg/m $/ \mathrm{m}^{2} \mathrm{xl}$, etoposide $200 \mathrm{mg} / \mathrm{m}^{2}$ ) dia $\times 4$, aracitin $200 \mathrm{mg} / \mathrm{m}^{2} /$ dia $x 4$, melfalan $140 \mathrm{mg} /$ $\left.m^{2} \times 1\right)$. No dia +12 apresentou dispnéia rapidamente progressiva, hipóxia $\left(\mathrm{PO}_{2}=45 \mathrm{mmHg}\right)$ e $\mathrm{RX}$ de tórax mostrando velamento difuso bilateral. Recebeu terapia empírica antibacteriana de amplo espectro (ceftazidima, amicacina e vancomicina) $e$ antifúngica (Anfotericina B). A biópsia broncoscópica revelou infiltrado inflamatório inespecífico e espessamento da membrana basal. Não foi isolado germe possívelmente causador de pneumonia infecciosa no lavado bronco-alveolar. Apresentou melhora discreta nos primeiros dia da terapia antimicrobiana, mas no dia +20 houve piora progressiva da dispnéia, a despeito da terapia instalada. No dia +38 necessitou de suporte ventilatório mecânico e evoluiu para óbito no dia +52 . A necrópsia revelou hemorragia extensa e desorganização dos espaços alveolares e infiltrado inflamatório mononuclear acompanhado de fibrose no interstício pulmonar. 
COMENTÁRIOS: quadros graves de pneumonite intersticial, como este, são associados, na literatura, a doses mais altas de BCNU do que as usadas neste paciente (acima de $475 \mathrm{mg} / \mathrm{Kg}^{20 a}$ ). Entretanto, a evolução clínica, a histopatologia pulmonar e a ausência de outras etiologias sugerem o diagnóstico de PI causada por uma reação ao BCNU.

\subsection{Toxicidade cardíaca}

A incidência de cardiotoxicidade pós-TCPH na literatura varia de 2 a $43 \%$, com taxas de mortalidade da ordem de $5 \%$ e está associada, principalmente, ao uso de altas doses de ciclofosfamida (>120 mg/Kg), que podem provocar arritmias, pericardite hemorrágica e até insuficiência cardíaca congestiva. A forma mais grave de cardiotoxicidade é a miocardite, que pode ocorrer até 10 dias após a administração da droga e é freqüentemente fatal. Não foram identificados fatores preditivos pré-TCPH capazes de definir os pacientes, principalmente se assintomáticos, sob risco de desenvolver esta complicação, mesmo se empregando provas sofisticadas como a ventriculografia isotópica ${ }^{(21)}$. Entretanto, a diminuição significativa (acima de 15 a $20 \%$ ) da amplitude dos complexos QRS no ECG, após a infusão de ciclofosfamida em altas doses, pode sugerir a evolução precoce para insuficiência cardíaca congestiva grave e a necessidade de uma reavaliação cuidadosa antes de prosseguir o condicionamento ${ }^{(21 a)}$. Os achados clínicos e eletrocardiográficos da cardiotoxicidade por ciclofosfamida são inespecíficos e, ao exame ecocardiográfico, os achados de pancardite são comuns. O tratamento consiste no suporte hemodinâmico da insuficiência cardíaca e, nos casos de toxicidade tardia, até o transplante cardíaco foi empregado com sucesso. Em nossa casuística de 170 transplantes (147 alogênicos e 23 autólogos), não identificamos qualquer paciente com diagnóstico provável ou confirmado de toxicidade cardíaca grave pela ciclofosfamida ou outro agente quimioterápico e não tivemos que suspender qualquer dose de ciclofosfamida no condicionamento devido ao comprometimento cardíaco.

\subsection{Outras toxicidades}

O uso de drogas nefrotóxicas, tanto no regime de condicionamento, quanto no suporte pós-transplante, pode levar a graus variáveis de disfunção renal, o que requer o ajuste precoce das doses destas drogas quando há evidências de disfunção renal. $\mathrm{O}$ sistema nervoso central pode ser comprometido também por agentes usados no condicionamento (como altas do- ses de bussulfan) e no período pós-transplante, como a ciclosporina. Alterações cutâneas decorrentes da toxicidade do condicionamento (irradiação, bussulfan, etc) são achados comuns pós-TCPH e podem causar confusão diagnóstica com outras dermatoses (infecciosas, alérgicas e do DECH).

\section{4- DOENÇA DO ENXERTO-CONTRA-HOSPE- DEIRO AGUDA}

As condições necessárias clássicas para que a DECH ocorra são: a) existência de incompatibilidade imunogenética entre o doador e o receptor; b) infusão de linfócitos $\mathrm{T}$ imunocompetentes do doador no receptor; c) incapacidade do receptor de rejeitar as células T do doador. As fases imunopatológicas envolvidas no desencadeamento da DECH vêm sendo intensamente estudadas e podem ser analisadas separadamente (Figura 1): 1) liberação de citocinas pró-inflamatórias (TNF e IL-1) pelos tecidos lesados durante o condicionamento, potencializando as reações imunológicas subsequentes; 2) reconhecimento de antígenos do hospedeiro pelos linfócitos $\mathrm{T}$ do doador e conseqüente ativação e proliferação das células $\mathrm{T}$ e de outras células imunocompetentes, como monócitos, macrófagos e células NK, 3) as células recrutadas e ativadas produzem uma intensa reação citotóxica contra as células do hospedeiro, potenciada por citocinas que interagem entre si, amplificando a resposta imunológica e causando uma verdadeira "tempestade de citocinas" (cytokine storm), envolvendo IL-2, interferon-gama, TNFa, IL-1 e outras ${ }^{(22)}$, com efeitos locais e sistêmicos.

A incidência mediana da DECH aguda de moderada a grave (graus II a IV, vide adiante) é de $40 \%$ e varia conforme os seguintes fatores de risco: idade elevada do receptor; regimes de condicionamento mais agressivos; grau de incompatibilidade HLA entre o doador e o receptor; grau de incompatibilidade nos antígenos secundários (minor) de histocompatibilidade; receptor de sexo masculino com doadora de sexo feminino; grau de paridade da doadora (aloimunizações); sorologia positiva para o CMV e conteúdo de células T do enxerto. Entretanto, esta última correlação não é observada, pelo menos para a DECH aguda, quando se usam CPH mobilizadas do sangue periférico com G-CSF, provavelmente porque esta citocina tem um efeito modulador sobre a resposta imunológica alogênica ${ }^{(22 a)}$.

Clinicamente, a DECH aguda caracteriza-se pelo comprometimento de três órgãos alvos principais: a pele, o trato gastrointestinal e o fígado. O estadiamento e a gradação da DECH determinam sua evolu- 


\section{Fisiopatologia da DECH}

\section{(I) Condicionamento do receptor Lesão Tecidual}

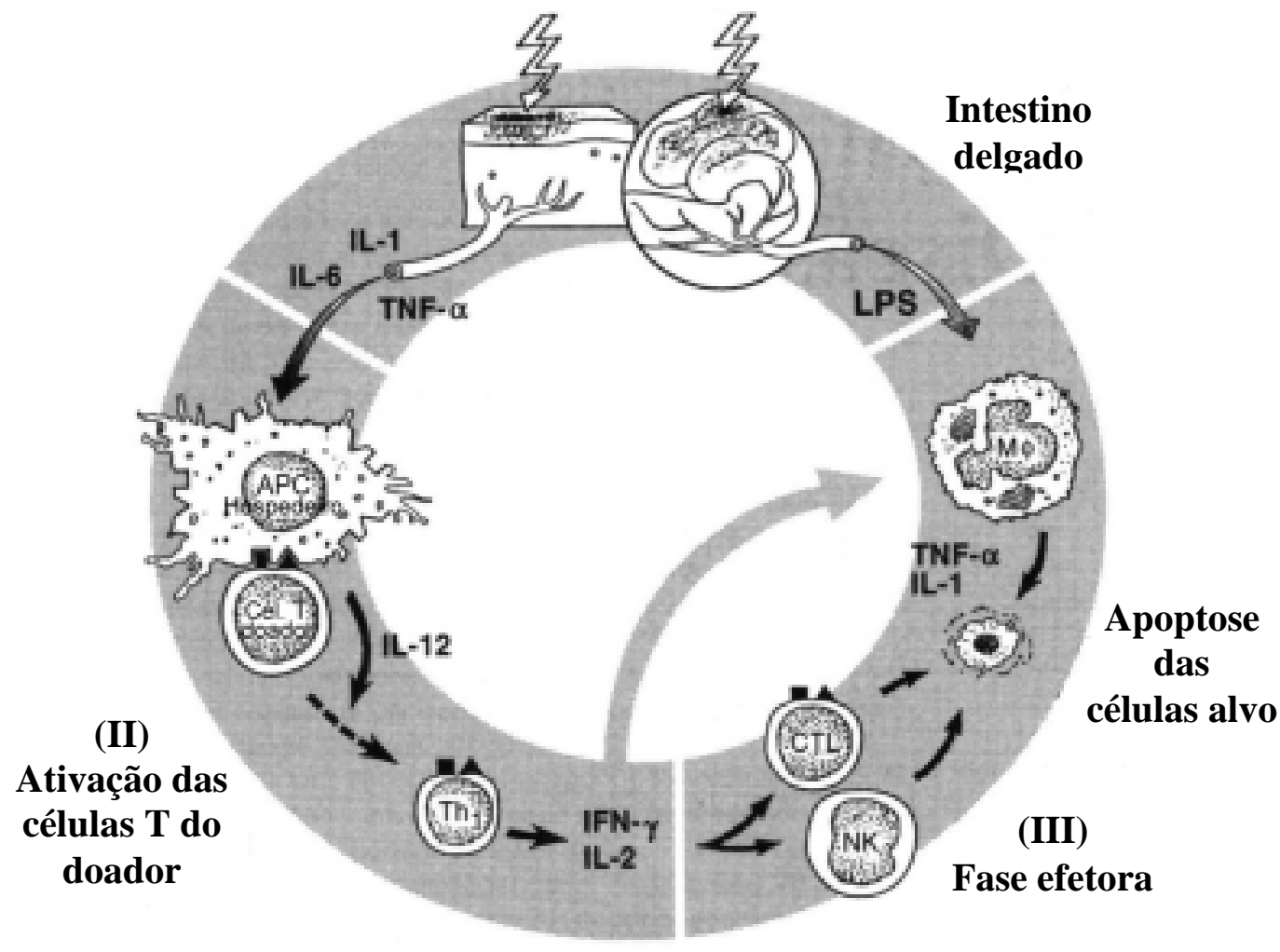

Figura 1: A fisiopatologia da DECH pode ser resumida em 3 fases: I) O regime de condicionamento, efeitos da doença básica e infecções prévias causam lesões teciduais; II) Células T do doador são ativadas por antígenos do receptor, liberando citocinas de padrão Th1; III) Linfócitos T lisam especificamente células do receptor, enquanto outras células citotóxicas são ativadas, inespecificamente por citocinas. Lipopolissacarídeos liberados do intestino amplificam o processo estimulando citocinas inflamatórias. Traduzida da ref. (22b).

\section{Tabela IV - Estadiamento da DECH aguda}

\begin{tabular}{|clll|}
\hline ESTADIO & PELE & FÍGADO & TRATO INTESTINAL \\
\hline 0 & Sem "rash" cutâneo. & Bilirrubina $<2 \mathrm{mg} / \mathrm{dl}$. & Diarréia $<500 \mathrm{ml} / \mathrm{dia}$. \\
\hline+ & $\begin{array}{l}\text { "Rash" maculopapular }<25 \% \\
\text { superfície corporal. }\end{array}$ & Bilirrubina $2-3 \mathrm{mg} / \mathrm{dl}$. & $\begin{array}{l}\text { Diarréia } 500-1000 \mathrm{ml} / \text { dia ou náuseas } \\
\text { persistentes. }\end{array}$ \\
\hline $2+$ & $\begin{array}{l}\text { "Rash" maculopapular 25 }-50 \% \\
\text { superfície corporal. }\end{array}$ & Bilirrubina 3-6 mg/dl. & Diarréia 1000-1500 ml/dia, \\
\hline $3+$ & Eritrodermia generalizada. & Bilirrubina 6-15 mg/dl. & Diarréia $>1500 \mathrm{ml} / \mathrm{dia}$. \\
\hline $4+$ & Bolhas e descamação. & Bilirrubina $>15 \mathrm{mg} / \mathrm{dl}$. & Dor abdominal +/- íleo paralítico. \\
\hline
\end{tabular}




\begin{tabular}{|c|c|c|c|c|}
\hline \multicolumn{5}{|c|}{ Tabela V - Gradação da DECH aguda } \\
\hline \multirow[b]{2}{*}{ GRAU } & \multicolumn{4}{|c|}{ ESTADIO } \\
\hline & PELE & FÍGADO & INTESTINO & $\begin{array}{l}\text { COMPROMETIMENTO } \\
\text { FUNCIONAL }\end{array}$ \\
\hline 0 (nenhum) & 0 & 0 & 0 & 0 \\
\hline I (leve) & $+\mathrm{a} 2+$ & 0 & 0 & 0 \\
\hline II (moderado) & $+a 3+$ & + & + & + \\
\hline III (grave) & $2+a 3+$ & $2+a 3+$ & $2+a 3+$ & $2+$ \\
\hline IV (risco de vida) & $2+a 4+$ & $2+a+4$ & $2+a+4$ & $3+$ \\
\hline
\end{tabular}

ção e prognóstico, bem como orientam a abordagem terapêutica da mesma. As Tabelas IV e V descrevem o sistema tradicional de classificação da DECH aguda, mas o IBMTR está testando um novo sistema (Revised Severity Index), que incorpora novos critérios, como manifestações gastro-intestinais altas e resposta terapêutica aos corticoesteróides, elimina os critérios subjetivos de avaliação do comprometimento funcional e, teoricamente, poderá distinguir com maior acurácia os efeitos da DECH dos de outras complicações, infecciosas e do condicionamento, que ocorrem nas fases iniciais do transplante.

O diagnóstico da DECH aguda baseia-se nos achados clínicos e na comprovação histológica da $\mathrm{DECH}$, especialmente da pele e do trato gastrointestinal. As biópsias cutâneas obtidas nas três primeiras semanas pós-transplante, freqüentemente, apresentam alterações decorrentes da toxicidade do regime de condicionamento e de reações a outras drogas, que não se diferenciam das alterações da DECH e têm, portanto, pouco valor diagnóstico. As alterações típicas de DECH na pele incluem: degeneração vacuolar de queratinócitos, com infiltrado linfocitário que pode evoluir para disceratose, necrose da camada basal (que, na verdade, apresenta sinais de apoptose à microscopia eletrônica), acantólise e epidermólise ${ }^{(23)}$.

As biópsias hepáticas não são realizadas de rotina, apenas em suspeitas de DECH hepática isolada para diferenciação de hepatopatias infecciosas, tóxicas ou medicamentosas. As células-alvo na DECH aguda são as do epitélio dos dutos biliares, que se apresentam apoptóticas com vacuolização citoplasmática, circundadas por infiltração linfocitária. Necrose hepatocelular pode estar presentes nos estádios mais graves. No trato intestinal, a apoptose do epitélio das criptas, com infiltração linfocitária, pode evoluir para desaparecimento das criptas e descamação do epitélio nos casos mais avançados.

A profilaxia da DECH inclui: a) a escolha do doador mais compatível; b) o tratamento imunossupressor do recipiente pós-transplante; c) a depleção parcial ou completa das células $\mathrm{T}$ do enxerto e d) a redução da intensidade do condicionamento. A escolha do "melhor" doador faz-se através da análise da compatibilidade entre os antígenos de histocompatibilidade principais (HLA) e, eventualmente, dos antígenos secundários, apesar da sua tipagem ainda possuir muitas limitações, mesmo nos centros mais avançados. Recorre-se também à escolha do doador do mesmo sexo, evitando, se possível, doadoras do sexo feminino para receptores do sexo masculino e, entre as doadoras do sexo feminino, aquelas com menor paridade, isto é, com menor chance de aloimunização.

Inúmeras são as abordagens imunossupressoras do receptor pós-TCPH para prevenir a ocorrência de DECH, o agente mais comumente utilizado é a ciclosporina A(CsA), que inibe especificamente a proliferação de células T e a produção e liberação de IL-2, além de reduzir a expressão de receptores de IL-2 e inibir a diferenciação de linfócitos T citotóxicos. Adroga é administrada associada ou não a outros agentes imunossupressores inespecíficos (metotrexate, corticosteróides, etc.), a partir do dia anterior à infusão de $\mathrm{CPH}$, comumentemente na dose de $3 \mathrm{mg} / \mathrm{kg} /$ dia por via endovenosa. Esta dose é ajustada a partir dos níveis séricos droga ou, quando não se dispõem destes níveis, pelos valores da creatinina sérica ${ }^{(24)}$. A CsA é continuada até por volta de 3 meses pós-TCPH, quando, então, é suspensa na ausência de DECH. Em casos de anemia aplástica, a CsA deve ser administrada por um período mais longo (até 18 meses) para evitar recaída da doença (vide Capítulo I), 
ao contrário, em neoplasias agressivas ou avançadas, ela pode ser suspensa mais precocemente e ser usada em dose mais baixa, numa tentativa de induzir um efeito imunológico anti-tumoral e reduzir as recidivas ${ }^{(24 a)}$. Outros agentes imunossupressores, como o tacrolimus (FK 506), o micofenolato de mofetil (MMF) e anticorpos monoclonais que bloqueiam o receptor de IL-2 têm sido estudados na profilaxia da DECH. Assim, a associação entre o MMF e a ciclosporina parece apresentar um efeito sinergístico na profilaxia da DECH em pacientes submetidos a TCPH de doadores não aparentados, enquanto que as vantagens da administração do tacrolimus não estão ainda completamente definidas ${ }^{(25,26,27)}$.

A depleção parcial ou completa de células T do enxerto tem sido utilizada como profilaxia da DECH, principalmente em transplantes entre indivíduos não aparentados, empregando-se inúmeras técnicas, porém o aumento da rejeição dos enxertos e da recidiva das doenças neoplásicas pós-TCPH limita o uso da depleção de células $\mathrm{T}$ a situações especiais com risco muito elevado de DECH ${ }^{(28)}$.

A redução da agressividade do condicionamento através do uso de regimes não mieloablativos ou subablativos (os chamados "mini-transplantes") tenta viabilizar a ocorrência de tolerância imunológica entre o hospedeiro e o doador, permitindo o desenvolvimento do efeito "enxerto-contra-tumor" sem o aparecimento da $\mathrm{DECH}^{(29,30)}$. Estudos preliminares com resultados bastante animadores foram descritos e várias investigações com populações mais significativas de pacientes estão em andamento. Entretanto, nem todos os regimes não-mieloablativos têm logrado a redução da incidência/gravidade da $\mathrm{DECH}$, principalmente quando se diminui a imunossupressão póstransplante como observado no caso clínico $n^{o}$ 8 . Assim, a reação inflamatória gerada pelo condicionamento pode não influenciar tanto a patogênese da doença, como se pensava antes, ou, então, este efeito parece depender do tipo de condicionamento e da profilaxia da DECH empregados.

O tratamento da DECH baseia-se na extensão e no grau de comprometimento dos diversos órgãos e sistemas afetados pela doença. Basicamente, são tratadas as DECH de grau >II e a droga de escolha para tratamento de primeira linha é a metilprednisolona, na dose de $2 \mathrm{mg} / \mathrm{kg} / \mathrm{d}$, em geral associada à CsA. A DECH refratária à corticoterapia apresenta uma alta mortalidade (de até $80 \%$ ) e a Tabela VI lista algumas das abordagens utilizadas no tratamento de segunda linha da DECH.

\section{CASO CLÍNICO ILUSTRATIVO $\mathbf{N}^{\circ} 8$}

Paciente de 15 anos, masculino, submetido em abril de 2000 a transplante alogênico não-mieloablativo de CPHSP de irmão HLA-idêntico por leucemia mielóide aguda refratária, sendo condicionado com fludarabina $30 \mathrm{mg} / \mathrm{m}^{2}$ por quatro dias, seguido de melfalan $70 \mathrm{mg} / \mathrm{m}^{2}$ por dois dias. A profilaxia da DECH foi feita apenas com ciclosporina-A $2.0 \mathrm{mg} / \mathrm{Kg}$ de peso real EV por infusão contínua a partir do dia -1 . Houve enxertia da medula óssea no dia +8 e, no mesmo dia, evoluiu com lesão cutânea do tipo eritrodérmica em tronco e membros inferiores, progredindo com eritrodermia generalizada e diarréia de até 4000 $\mathrm{ml}$ ao dia. Recebeu terapia com prednisona $2.0 \mathrm{mg} /$ $\mathrm{Kg} / \mathrm{d}$ e aumento da dose de ciclosporina para 3 $\mathrm{mg} / \mathrm{Kg} / \mathrm{d}$. Não houve melhora do quadro e foi iniciada terapia de segunda linha com gamaglobulina anti-linfocitária (Pasteur-Mérieux) na dose de 15 $\mathrm{mg} / \mathrm{kg}$ em dias alternados $x 6$, produzindo, então, melhora das lesões cutâneas e da diarréia, que cessou em 4 dias. No dia +20 , o paciente evoluiu com insuficiência respiratória, necessitando de assistência ventilatória mecânica, síndrome do desconforto respiratória do adulto (SARA) e pneumonia por provável superinfecção. Foi a óbito no dia +42 após o transplante.

COMENTÁRIOS: Apesar de receber um regime de condicionamento pretensamente nãomieloablativo, este jovem paciente desenvolveu DECH aguda grau III, que apenas respondeu a terapia imunossupressora de segunda linha, a

Tabela VI - Aqentes imunossupressores utilizados na prevenção e tratamento da DECH aguda

AGENTES PROFILAXIA TRATAMENTO

Depleção de células $T$

Metotrexate

Ciclosporina A

Corticosteróides

ATG

Anticorpos monoclonais

Tacrolimus

Micofenolato de mofetil

$+$

$+$

$+$

$+\quad+$

$+\quad+$

+: utilizado clinicamente; -: não utilizado clinicamente 
qual, muito provavelmente, predispôs às complicações infecciosas que causaram o óbito.

\section{5 - CONCLUSÕES}

As complicações agudas do TCPH dependem da agressividade do regime de condicionamento e do grau de lesão endotelial provocada por ele, bem como da fase da doença de base na época do transplante, das condições clínicas do paciente e do tipo de transplante realizado (autólogo ou alogênico, aparentado ou não, de medula óssea ou de sangue periférico, etc). Estratégias que visam à identificação e controle destes fatores estão sendo desenvolvidas e algumas delas, como os transplantes com regimes nãomieloablativos, certamente contribuirão para a melhoria da evolução clínica destes pacientes e das taxas de sobrevida a longo prazo.

\section{AGRADECIMENTOS}

À FAEPA/HCRP e à FUNDHERP pelo suporte contínuo às atividades da Unidade de TMO do HCRP e pela aquisição de material bibliográfico e à Dra. Mary E. Flowers pela revisão do manuscrito.

PATON EJA; COUTINHO MA \& VOLTARELLI JC. Diagnosis and treatment of acute complications of hematopoietic stem cell transplantation. Medicina, Ribeirão Preto, 33: 264-277, jul./set. 2000.

ABSTRACT: In this review, we discuss principles of diagnosis and treatment of main noninfectious acute complications of hematopoietic stem cell transplantation: pancytopenia, ABO incompatibility, mucositis, venocclusive disease of the liver, hemorrhagic cystitis, interstitial pneumonia, cardiac and pulmonary toxicity and acute graft-versus-host disease. Eight clinical cases, taken from the series of our BMT Unit, are briefly presented to illustrate particular aspects of the diseases discussed in the article.

UNITERMS: Bone Marrow Transplantation. Graft VS Host Disease. Mortality; transplantation.

\section{REFERÊNCIAS BIBLIOGRÁFICAS}

1 - BENJAMIN S. Early history of bone marrow transplantation. In:TRELEAVEN J \& WIERNIK P,ed. Color atlas and text of bone marrow transplantation. P. Mosby-Wolfe, London, p.9-10, 1995.

2 - LONG GD. Regimen related toxicity - first 30 days early toxicity of high-dose therapy. In: BURT RK; DEEG HJ; LOTHIAN ST \& SANTOS GW. Bone marrow transplantationotation. Landes Company, Austin , p. 504-514, 1998.

3 - RIBAUD P. Early complications. In: APPERLEY J; GLUCKMAN E; GRATWOHL A \& CRADDOCK Blood and marrow transplantation. revised edition. European School of Haematology, p.1148-159, 1999.

4 - LANGE W \& MERTELSMANN R. Use of recombinant growth factors after hamatopoietic cell transplantation. In: THOMAS ED; BLUME KG \& FORMAN SJ. ed. Hematopoietic cell transplantation. $2^{\text {nd }}$ edition, Blackwell Science, Boston, p.493502,. 1999.

4a-KLAESSON S. Clinical use of rHuEPO in bone marrow transplantation. Med Oncol 16: 2-7, 1999.

5 - MCCULLOUGH J. Principles of transfusion support before and after hematopoietic cell transplantation. In: THOMAS ED; BLUME KG \& FORMAN SJ. ed. Hematopoietic cell transplantation. $2^{\text {nd }}$ edition, Blackwell Science, Boston, p.685703, 1999.

6 - PATON EJA. Terapia transfusional em neoplasias e no transplante de medula óssea. Medicina, Ribeirão Preto, 26: 543-554, 1993.

7 - FIGOLI F; CHIARION SILENI V; GULISANO M; MAGGIAN P \& FOSSER V. Leucovorin calcium enhancement of mucositis after continuous infusion fluorouracil and short infusion cisplatin. J Clin Oncol 7:680-681, 1989.

8 - STRASSER SI \& MCDONALD GB. Gastrointestinal and hepatic complications. In: THOMAS ED; BLUME KG \& FORMAN SJ. ed. Hematopoietic cell transplantation. $2^{\text {nd }}$ edition, Blackwell Science, Boston, p627-658, 1999.

9 - YANG CC; HURD DD; CASE LD \& ASSIMOS DG. Hemorrhagic cystitis in bone marrow transplantation. Urology 44:322328,1994

10 - ATTAL M; HUGUeT F \& RUBIE H. Prevention of hepatic veno-oclusive disease after bone marrow transplantation by continuous infusion of low-dose heparin: a prospective randomized trial. Blood 79: 2834-2840, 1992. 
11 - OR N; NAGLER A \& SHPILBERG O: Low molecular weight heparin for the prevention of veno-oclusive disease of the liver in bone marrow transplantation patients. Transplantation 61: 1067-1071, 1996.

12 - LEE LH; CHIANG T \& LINN YC. Low molecular weight heparin in prophylaxis of veno-oclusive disease in patients undergoing bone marrow transplantation. Blood 88 : 1645, 1996 Suppl.1.

13 - GLUCKMAN E; JOLIVET I \& SCROBOHACI ML: Use of prostaglandin E1 for prevention of liver veno-oclusive disease in leukaemic patients treated by allogeneic bone marrow transplantation. Br J Haematol 74: 277-281, 1990.

14 - COMCOWICH AS; SPITZER TR\& TSUNODA SM. Ursodiol to prevent hepatic veno-oclusive disease. Ann Parmacotther 31: 1249-1252, 1997.

15 - OHASHI K; TANABE J; WATANABE R; TANAKA T; SAKAMAKI $\mathrm{H}$; MARUTA A; OKAMOTO S; AOTSUKA N; SAITO K; NISHIMURA M; OH H; MATSUZAKI M; TAKAHASHI S \& YONEKURA $S$. The japanese multicenter open randomized trial of Ursodeoxycholic Acid prophylaxis for hepatic venooclusive disease after stem cell transplantation. Am J Haematol 64: 32-38, 2000.

16 - BEARMAN SI; LEE JL; BARON AE \& MCDONALD GB: Treatment of hepatic veno-oclusive disease with recombinant human tissue plasminogen activator and heparin in 42 marrow transplant patients. Blood 89: 1501-1506, 1997.

17 - RICHARDSON PG; ELIAS AD; KRISHNAN A; WHEELER C; NATH R; HOPPENSTEADT D; KINCHLA NM; NEUBERG D; WALLER EK; ANTIN JH; SOIFFFER R; VREDENBURGH J; LILL M; WOOLFREY AE; BEARMAN SI; IACOBELLI M; FAREED J \& GUINAN EC. Treatment of severe veno-oclusive disease with defibrotide: compassionate use results in response without significant toxicity in a high risk population. Blood 92: 737-744, 1998.

18 - LOHR F; WENZ F; SCHRAUBE P ;FLENTJE M; HAAS R; ZIERHUT D; FEHRENTZD; HUNSTEIN W \& WANNENMACHER $M$.: Lethal pulmonary toxicity after autologous bone marrow transplantation/peripheral blood stem cell transplantation for hematological malignancies. Radiother Oncol 48: 45-55, 1998.

19 - ALAM S \& CHAN K M. Noninfectious pulmonary complications after organ transplantation. Curr Opin Pulm Med 2:412-418, 1996 .

20 - CRAWFORD SW. Critical care and respiratory failure. In: THOMAS ED; BLUME KG \& FORMAN SJ. ed. Hematopoietic cell transplantation. $2^{\text {nd }}$ edition, Blackwell Science , Boston, p.712-722, 1999.

20a - RUBIO C; HILL ME; MILAN S; O'BRIEN ME \& CUNNINGHAM D. Idiopathic pneumonia syndrome after high-dose chemotherapy for relapsed Hodgkin's disease. Br J Cancer 75: 1044-1048, 1997..

21 - HERTENSTEIN B; STEFANIC M; SCHMEISER T; SCHOLZ M ; GÖLLER V; CLAUSEN M; BUNJES D; WIESNETH M; NOVOTNY J \& KOCHS M: Cardiac toxicity of bone marrow transplantation: predictive value of cardiologic evaluation before transplant. J Clin Oncol 12:998-1004, 1994.

21a - CAZIN B; GORIN MC; CAPORTE SP; GALLET B; DOVAY L; COPEZ M; MAJMAN A \& DUHAMEL G. Cardiac complications after bone marrow transplantation. A report on a series of 63 consecutive transplantations. Cancer 57: 2061-
2069, 1986.

22 - SULLIVAN KM. Graft-versus-host-disease. In: THOMAS ED; BLUME KG \& FORMAN SJ, ed. Hematopoietic cell transplantation. $2^{\text {nd }}$ edition, Blackwell Science, Boston, p.515536, 1999.

22a - ARPINATTI A, GRREN CL; HEIMFIELD S; HEUSER JE \& ANASETTI C. Granulocyte-colony stimulating factor mobilizes $T$ helper 2-inducing dendritic cells. Blood 95: 24842490, 2000.

22b - FERRARA J; ANTIN JH. The pathophysiology of graft-versus-host disease. In: THOMAS ED; BLUME KG \& FORMAN SJ. ed. Hematopoietic cell transplantation. $2^{\text {nd }}$ edition, Blackwell Science, Boston, p.305-315, 1999.

23 - CHAO NJ. Graft versus host disease In: BURT RK; DEEG HJ; LOTHIAN ST \& SANTOS GW. Bone marrow transplantationotation. Landes Company, Austin, p478498, 1998.

24 - DEVERGIE, A; JANIN, A: Graft versus host disease. In: APPERLEY J; GLUCKMAN E; GRATWOHL A \& CRADDOCK Blood and marrow transplantation. revised edition . European School of Haematology, p.130-147, 1999.

24a - CARLENS S; ASCHAN J; REMBERGER M; DILBER M \& RINGDEN O. Low dose cyclosporine of short duration increases the risk of mild and moderate GVHD and reduces the risk of relapse in HLA-identical sibling marrow transplant recipients eith leukemia. Bone Marrow Transplant 24: 629-635, 1999.

25 - YU C; SEIDEL K; NASH RA; DEEG HJ; SANDMAIER BM; BARSOUKOV A; SANTOS E \& STORB R. Synergism between mycophenolate mofetil and cyclosporine in preventing graft-versus-host disease among lethally irradiated dogs given DLA-nonidentical unrelated marrow grafts. Blood 91: 2581-2587, 1998..

26 - WINGARD JR; NASH RA; RATANATHARATHORN V; FAY JW; KLEIN JL; PRZEPIORKA D; MAHER RM; DEVINE SM; BOSWELL G; BEKERSKY I \& FITZSIMMONS W: Lack of interaction between tacrolimus (FK506) and methotrexate in bone marrow transplant recipients Bone Marrow Transplant 20:49-51, 1997.

27 - JACOBSON P; UBERTI J; DAVIS W \& RATANATHARATHORN V. Tacrolimus: a new agent for the prevention of graft-versus-host disease in hematopoietic stem cell transplantation. Bone Marrow Transplant 22:217-225, 1998.

28 - BARRETT AJ; MAVROUDIS D; TISDALE J; MOLLDREM J; CLAVE E; DUNBAR C; COTTLER-FOX M; PHANG S; CARTER C; OKUNNIEFF P; YOUNG NS \& READ EJ. T cell-depleted bone marrow transplantation and delayed $T$ cell add-back to control acute GVHD and conserve a graft-versus-leukemia effect. Bone Marrow Transplant 21:543-551, 1998.

29 - CHAMPLIN R; KHOURI I \& GIRALT S. Graft-vs-malignancy with allogeneic blood stem cell transplantation: a potential primary treatment modality. Pediatr Transplant 3::52-58, 1999.Suppl.1 (-HD-).

30 - CARELLA AM; GIRALT S \& SLAVIN S. Low intensity regimens with allogeneic hematopoeitic stem cell transplantation as treatment of hematological neoplasia. Haematologica 85: 304-313, 2000.

Recebido para publicação em 13/06/2000

Aprovado para publicação em 11/07/2000 